\title{
BMJ Open Association between limiting longstanding illness in mothers and their children: findings from the UK Millennium Cohort Study
}

\author{
Dana Šumilo, Jennifer J Kurinczuk, Maggie E Redshaw, Ron Gray
}

To cite: Šumilo D, Kurinczuk JJ, Redshaw ME, et al. Association between limiting longstanding illness in mothers and their children: findings from the UK Millennium Cohort Study. BMJ Open 2013;3:e004190. doi:10.1136/bmjopen-2013004190

- Prepublication history and additional material for this paper is available online. To view these files please visit the journal online (http://dx.doi.org/10.1136/ bmjopen-2013-004190).

Received 7 October 2013 Revised 8 November 2013 Accepted 14 November 2013

CrossMark

Policy Research Unit in Maternal Health \& Care, National Perinatal Epidemiology Unit, Nuffield Department of Population Health, University of Oxford, Oxford, UK

Correspondence to Dr Ron Gray; ron.gray@npeu.ox.ac.uk

\section{ABSTRACT}

Objective: To explore the association between maternal disability as measured by the presence of a limiting longstanding illness (LLI) 9 months postpartum and subsequent child health at the age of 7 years.

Design: Nationally representative prospective longitudinal study.

Setting: England, Scotland, Wales and Northern Ireland. Participants: Secondary analysis of data on 11807 mother-child pairs recruited to the UK Millennium Cohort Study. Baseline interviews with mothers were carried out in 2001-2002. When the children were 7 years old, the follow-up survey included questions about limiting longstanding health conditions in the child.

Primary outcome measure: Any longstanding condition that was reported to limit the children's activities in any way.

Results: Nearly $7 \%$ of all children were reported to have an LLI at the age of 7 years. The majority $(88.1 \%, 95 \%$ $\mathrm{Cl} 85.6 \%$ to $90.2 \%$ ) of children whose mother was disabled did not have an LLI themselves. The children of disabled mothers, however, had higher odds of LLI (OR=1.9, 95\% $\mathrm{Cl} 1.5$ to 2.5 ) independently of different maternal, pregnancy and birth characteristics and breast feeding duration. Inclusion of poverty measures in the model did not significantly affect the odds (OR=1.8, 95\% $\mathrm{Cl} 1.4$ to 2.4), suggesting that maternal LLI around the time of birth increases the odds of child LLI at the age of 7 years independently of starting life in poverty.

Conclusions: There is a strong positive association between maternal and child LLI. Health professionals should work together with social care and other relevant service providers to identify the individual needs of disabled parents and provide adequate support throughout the pregnancy and after the child is born. Further research is important to clarify the exact nature of the associations for different types of maternal and child disability.

\section{INTRODUCTION}

Limiting longstanding illness (LLI) in women of childbearing age is relatively common with a prevalence of $8 \%$ in 16-year-old to 44-year-old women reported by the 2001 Population Census for England. ${ }^{1}$ Health-

\section{Strengths and limitations of this study}

- The findings are based on a very large prospectively followed sample of mothers and children across the UK.

- Limiting longstanding illness in children is examined independently of other maternal and child characteristics and socio-economic disadvantage.

- Information about maternal limiting longstanding illness relied on self-reporting. This, however, is a common practice in population health surveys.

related behaviours of parents, environmental and genetic factors have an influence on the child health and development. The role of parental health and disability independently of health behaviours and socioeconomic disadvantage is less well researched. ${ }^{2}$ Early childhood experiences can have lifelong effects on health and well-being. ${ }^{3}$ Poor health during childhood is linked with lower educational attainment, socioeconomic status and poor health in adulthood independently of parental socioeconomic circumstances, thus potentially contributing to the intergenerational transmission of socioeconomic disadvantage. ${ }^{4}$ The government in England recognises that an early support for families is important for successful child development and has set a vision to help "professionals to use all interactions with families as opportunities to identify any additional needs and offer further help." 5

This study aims to add to the current evidence base about the groups of parents who may have unmet needs that would have to be addressed to reduce the child health inequalities. It examines the relationship between maternal disability as measured by the presence of an LLI 9 months postpartum and child LLI at the age of 7 years and explores whether this relationship can be attributed to the experience of different dimensions of poverty in the first year of life. 


\section{METHODS}

Data from the UK Millennium Cohort Study (MCS), the nationally representative longitudinal survey of children and their families, were analysed. The design of the MCS and data collection have been described elsewhere in detail. ${ }^{6-8}$ In summary, the MCS sample was drawn from electoral wards across the UK and was clustered geographically and stratified to achieve an adequate representation of areas of high child poverty and ethnic diversity. The families were identified from the UK Child Benefit System which covers practically all children except those whose residency status is uncertain or temporary (such as children of asylum seekers and members of foreign armed forces). Trained interviewers carried out baseline interviews with 18552 families during home visits in 2001-2002 when the infants were 9 months old. The MCS sample did not include children who had died in the first 9 months after birth; infant mortality, however, was less than $1 \% .^{9}$ Follow-up surveys took place when the children were 3,5 and 7 years old.

We restricted this study to mother-child pairs where the natural mother was the main respondent at baseline and singleton births. When the infants were 9 months old, the mothers were asked: "Do you have a longstanding illness, disability or infirmity. By longstanding I mean anything that has troubled you over a period of time or that is likely to affect you over a period of time?" If an affirmative answer was given, they were asked further "What is the matter with you?" and "Does this illness or disability limit your activities in any ways?" The coding of reported health conditions was undertaken at the Centre for Longitudinal Studies, Institute of Education, University of London using the tenth revision of the International Classification of Diseases (ICD-10). Other baseline information were collected including maternal demographic, socioeconomic and lifestyle details, information about pregnancy and child characteristics at birth. When the children were 7 years old, the main respondents were asked the same questions about the longstanding health conditions in the child. The outcome measure used in this paper is any longstanding condition that was reported to limit child's activities in any way.

From the total eligible sample for this study ( $n=18$ 231), 72.2\% (13 156) responded when the cohort children were 7 years old. The attrition was not higher among families where the mother had an LLI; $72.5 \%$ $(1307 / 1803)$ of these families responded when the children were aged 7 years. The final analysis included 11807 mother-child pairs with complete data on all the relevant variables (figure 1 ).

Logistic regression analysis was performed in Stata SE V.11.1 (Stata Corporation, Texas, USA) using survey commands with sampling and non-response weights to allow for the clustered, stratified sample design and to adjust for non-response at baseline and attrition between the study years. ${ }^{7}$ If not specified otherwise, weighted estimates are reported. First, an unadjusted model was used to examine the relationship between maternal LLI and child LLI. The results were then contrasted with a second model adjusting for maternal characteristics (age at delivery, ethnicity, educational level and socioeconomic position at baseline, parity, pregnancy planning, smoking during pregnancy), child characteristics (gender, gestational age at birth and birth weight) and duration of breast feeding. Finally in a fully adjusted model, the association between poverty status during the first year of life and child LLI was examined. Income poverty was defined as having a net family income below $60 \%$ of the national median (allowing for family size and composition using the modified Organisation for
Figure 1 Participant flow diagram (actual numbers).

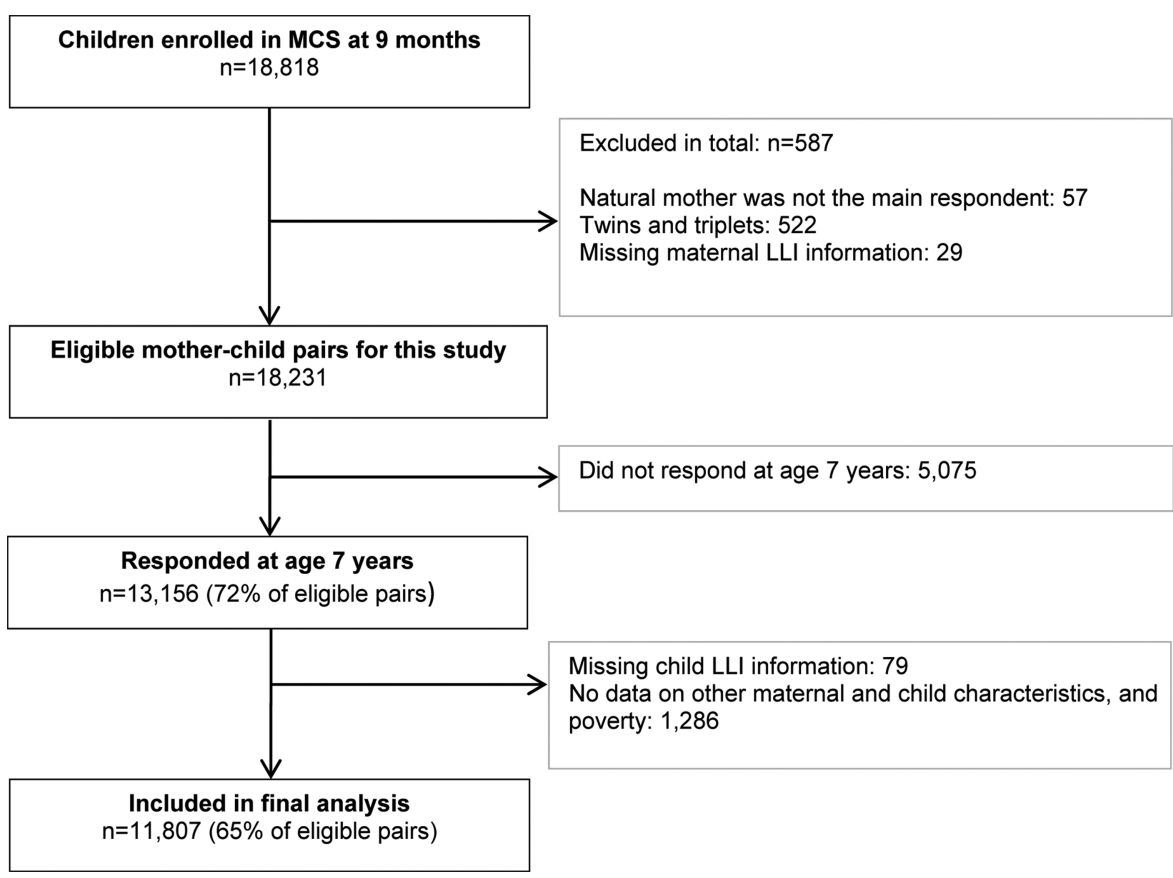


Economic Co-operation and Development equivalence scale). Subjective poverty was defined as the mother reporting finding it quite or very difficult to manage financially or just about getting by. ${ }^{10} 11$

\section{RESULTS}

The population characteristics by maternal LLI status 9 months after giving birth are shown in table 1 . The most commonly reported LLIs were different musculoskeletal disorders, asthma and recurrent depressive disorder. More detailed description of the LLIs of the MCS participants has been published previously. ${ }^{12}$ Apart from maternal age at delivery, ethnicity and child's sex, all other characteristics between mothers with and without an LLI were statistically significantly different at $5 \%$ significance level.

Overall, 6.6\% (772/11 699) of children were reported to have an LLI at the age of 7 years. The most frequently reported LLIs in childhood were diseases of the respiratory system with asthma being the most common. Mental and behavioural disorders (especially pervasive developmental disorders) and diseases of the ear and mastoid process (including hearing loss) were also relatively common.

In the unadjusted analysis, 7-year-old children of LLI mothers had significantly higher odds $(\mathrm{OR}=2.11,95 \%$ CI 1.67 to 2.68) of having an LLI themselves compared with their counterparts whose mothers did not have an LLI 9 months postpartum (table 2). Living in poverty in the first year of life was associated with higher odds of having an LLI aged 7 years (OR=1.62, 95\% CI 1.35 to 1.94 for income poverty; OR=1.62, 95\% CI 1.37 to 1.92 for subjective poverty).

In the second model adjusting for other maternal, as well as pregnancy and child characteristics, a nonsignificant attenuation in the relationship between maternal LLI and child LLI was observed $(\mathrm{OR}=1.92$, $95 \%$ CI 1.50 to 2.46 ). Having a mother without any academic qualifications, who smoked throughout pregnancy, being a boy and having a low birth weight also remained significant predictors of child LLI.

In the final model (which included the income and subjective poverty status around the time of birth, and all the variables of the previous model) there was a slight further attenuation in the relationship between the maternal and child LLI; the association, however, remained statistically significant $(\mathrm{OR}=1.84,95 \%$ CI 1.44 to 2.36). Smoking throughout pregnancy, being a boy and lower birth weight remained significant predictors of child LLI. Income poverty, as measured by family income being below $60 \%$ of the national median, was associated with higher odds of having a child with a limiting long-term condition ( $\mathrm{OR}=1.18,95 \%$ CI 0.93 to $1.50)$ independently of other factors; but this finding was not statistically significant. Children who were from subjectively poor families had significantly higher odds $(\mathrm{OR}=1.32,95 \%$ CI 1.09 to 1.58$)$ of having an LLI than children who were from families living comfortably or 'doing all right' when the child was born.

\section{DISCUSSION}

Most of the children born to mothers with an LLI did not have an LLI themselves (as measured at the age of 7 years), despite a higher proportion of these children experiencing a socioeconomic disadvantage in the first year of life, maternal smoking throughout pregnancy, preterm birth, lower birth weight and shorter duration of breastfeeding than children whose mothers did not have an LLI (reported 9 months after giving birth). Nevertheless, these children had significantly higher odds of having a limiting longstanding health condition compared with children whose mothers did not have an LLI even after adjusting for all likely confounders about which information had been collected (different maternal, pregnancy and child characteristics including starting life in poverty).

The strengths of this study include a large nationally representative sample of mothers and babies with information on maternal characteristics such as maternal LLI status and exposure to poverty collected at the beginning of the study. The cohort was followed prospectively and the child LLI status was assessed when the children were aged 7 years. To minimise the effects of loss to follow-up, non-response weights were used in all analyses to take into account the factors associated with response. ${ }^{8}$ Nevertheless, the impact of poverty may have been underestimated, as poorer families were less likely to respond. ${ }^{13}{ }^{14}$ Information regarding the presence or absence of maternal LLI was provided by mothers themselves who in most cases also provided information on the child's LLI at the age of 7 years. This may have introduced some degree of bias. There is evidence that certain conditions, for example, mental health problems may be under-reported. ${ }^{15}$ Self-reported LLI, however, has been found to be a valid indicator of morbidity in adult populations, including in young adults. ${ }^{16} \mathrm{~A}$ high level of agreement has been reported between selfreports of chronic illness and clinical assessments. ${ }^{15}$ Adult-reported child LLI status has also been frequently used as a measure of disability in children in a range of population surveys. It captures a broad spectrum of health issues and impairments; however, it does not take into account child's age and development, and does not capture the multidimensional nature of the disability. ${ }^{17}$ The focus of this study in terms of maternal characteristics was on the mother's limiting health condition reported 9 months after giving birth and longstanding in nature. It is, therefore, likely that most of such disabling conditions were present also during pregnancy. Thus in the majority of cases the exposure would have preceded the birth and onset of LLI in a child. It is, however, possible that a small proportion of women developed an LLI after the child was born. Nevertheless, its effects may still have an impact on the child. 
Table 1 Description of the study population (percentages)

\begin{tabular}{|c|c|c|}
\hline \multirow[b]{2}{*}{ Characteristics } & \multicolumn{2}{|c|}{ Maternal limiting longstanding illness } \\
\hline & $\begin{array}{l}\text { Yes }\left(n=1130^{\star}\right) \\
\text { Per cent }(95 \% \mathrm{Cl})\end{array}$ & $\begin{array}{l}\text { No }\left(n=10569^{\star}\right) \\
\text { Per cent }(95 \% \mathrm{Cl})\end{array}$ \\
\hline \multicolumn{3}{|l|}{ Age at delivery in years $(p=0.052)$} \\
\hline$<25$ & 26.3 (23.3 to 29.6$)$ & 23.1 (21.6 to 24.8$)$ \\
\hline 25-34 & 52.9 (49.5 to 56.3$)$ & 57.0 (55.7 to 58.3$)$ \\
\hline \multicolumn{3}{|l|}{ Ethnic group $(p=0.942)$} \\
\hline White & 89.1 (85.7 to 91.7$)$ & 89.2 (86.7 to 91.2$)$ \\
\hline Other ethnic group & 10.9 (8.3 to 14.3$)$ & 10.8 (8.8 to 13.3$)$ \\
\hline \multicolumn{3}{|l|}{ Qualification $(p<0.001)$} \\
\hline Higher degree/first degree/diploma & $18.9(16.4$ to 21.6$)$ & 26.7 (24.6 to 28.9$)$ \\
\hline A/AS/S levels & $9.0(7.3$ to 11.0$)$ & 9.5 (8.9 to 10.2$)$ \\
\hline \multicolumn{3}{|l|}{ Socioeconomic class $(p<0.001)$} \\
\hline Managerial/professional occupation & 29.4 (17.9 to 23.0$)$ & 20.3 (28.4 to 32.4$)$ \\
\hline Intermediate occupation & $18.0(15.4$ to 21.0$)$ & 22.3 (21.2 to 23.4$)$ \\
\hline Routine/manual occupation & $50.0(46.5$ to 53.5$)$ & 39.6 (37.6 to 41.7$)$ \\
\hline Never worked/long-term unemployed & 11.7 (9.5 to 14.2$)$ & 7.7 (6.6 to 9.0$)$ \\
\hline \multicolumn{3}{|l|}{ Pregnancy characteristics } \\
\hline \multicolumn{3}{|l|}{ Whether this was the first baby $(p=0.005)$} \\
\hline No & 62.2 (58.6 to 65.6$)$ & 57.0 (55.8 to 58.3$)$ \\
\hline Yes & 37.8 (34.4 to 41.4$)$ & 43.0 (41.7 to 44.2$)$ \\
\hline \multicolumn{3}{|l|}{ Planning pregnancy $(p<0.001)$} \\
\hline Pregnancy was a surprise & 52.8 (49.4 to 56.2$)$ & 43.0 (41.6 to 44.3$)$ \\
\hline \multicolumn{3}{|l|}{ Mother's smoking status during pregnancy $(p<0.001)$} \\
\hline \multicolumn{3}{|l|}{ Gestational age $(p<0.001)$} \\
\hline Very preterm $<32$ weeks & $1.2(0.7$ to 2.2$)$ & $0.8(0.6$ to 1.0$)$ \\
\hline Preterm 32-36 weeks & $9.9(7.9$ to 12.4$)$ & 5.7 (5.2 to 6.3$)$ \\
\hline Term 37-42 weeks & $88.9(86.1$ to 91.2$)$ & 93.5 (92.9 to 94.1$)$ \\
\hline Mean birth weight in grams $(p<0.001)$ & 3309 (3268 to 3350$)$ & 3383 (3369 to 3397$)$ \\
\hline \multicolumn{3}{|l|}{ Duration of breast feeding $(p<0.001)$} \\
\hline Never breast fed & 35.1 (31.9 to 38.4$)$ & 32.1 (30.2 to 34.1$)$ \\
\hline$<1$ week & 11.4 (9.5 to 13.8$)$ & 9.7 (9.0 to 10.5$)$ \\
\hline 1 week-3 months & $28.5(25.7$ to 31.5$)$ & 25.2 (24.2 to 26.3$)$ \\
\hline$>3$ months & 25.0 (22.0 to 28.2$)$ & 32.9 (30.8 to 35.1$)$ \\
\hline \multicolumn{3}{|c|}{ Child had a limiting longstanding illness at 7 years of age $(p<0.001)$} \\
\hline No & 88.1 (85.6 to 90.2$)$ & $94.0(93.4$ to 94.5$)$ \\
\hline Yes & $11.9(9.8$ to 14.4$)$ & $6.0(5.5$ to 6.6$)$ \\
\hline \multicolumn{3}{|l|}{ Poverty } \\
\hline \multicolumn{3}{|l|}{ Income poverty $(p<0.001)$} \\
\hline Family income above $60 \%$ of the national median & 57.7 (53.8 to 61.6$)$ & 70.7 (68.8 to 72.6$)$ \\
\hline Family income below $60 \%$ of the national median & 42.3 (38.4 to 46.2$)$ & 29.3 (27.4 to 31.2$)$ \\
\hline \multicolumn{3}{|l|}{ Subjective poverty $(p<0.001)$} \\
\hline Subjectively not poor & $45.8(42.2$ to 49.5$)$ & $63.2(61.6$ to 64.8$)$ \\
\hline Subjectively poor & $54.2(50.5$ to 57.8$)$ & 36.8 (35.2 to 38.4$)$ \\
\hline
\end{tabular}


Table 2 Prevalence of child limiting longstanding illness by maternal, pregnancy, child characteristics and poverty dimensions, and the results of logistic regression analysis

\begin{tabular}{|c|c|c|c|c|c|c|c|}
\hline Characteristics & $\begin{array}{l}\text { Prevalence of child } \\
\text { limiting } \\
\text { longstanding } \\
\text { illness in per cent } \\
(95 \% \mathrm{Cl})\end{array}$ & $\begin{array}{l}\text { Unadjusted } \\
\text { OR }(95 \% \mathrm{Cl})\end{array}$ & $\begin{array}{l}p \\
\text { Value }\end{array}$ & $\begin{array}{l}\text { Partially adjusted } \\
\text { OR }^{\star}(95 \% \mathrm{Cl})\end{array}$ & $\begin{array}{l}p \\
\text { Value }\end{array}$ & $\begin{array}{l}\text { Adjusted } \\
\text { OR† }(95 \% \mathrm{Cl})\end{array}$ & $\begin{array}{l}p \\
\text { Value }\end{array}$ \\
\hline \multicolumn{8}{|l|}{ Maternal characteristics } \\
\hline \multicolumn{8}{|l|}{ Maternal limiting longstanding illness } \\
\hline No & 6.0 (5.5 to 6.6$)$ & 1 & & 1 & & 1 & \\
\hline Yes & $11.9(9.8$ to 14.4$)$ & 2.11 (1.67 to 2.68$)$ & $<0.001$ & $1.92(1.50$ to 2.46$)$ & $<0.001$ & 1.84 (1.44 to 2.36$)$ & $<0.001$ \\
\hline \multicolumn{8}{|l|}{ Age at delivery in years } \\
\hline$<25$ & $8.0(6.8$ to 9.4$)$ & 1 & & 1 & & 1 & \\
\hline $25-34$ & 6.1 (5.5 to 6.9$)$ & 0.75 (0.61 to 0.92$)$ & 0.006 & $0.91(0.71$ to 1.15$)$ & 0.43 & 0.94 (0.74 to 1.19$)$ & 0.595 \\
\hline $35+$ & $6.3(5.2$ to 7.5$)$ & 0.77 (0.59 to 0.99$)$ & 0.044 & $0.96(0.70$ to 1.31$)$ & 0.781 & $0.99(0.73$ to 1.36$)$ & 0.973 \\
\hline \multicolumn{8}{|l|}{ Ethnic group } \\
\hline White & $6.6(6.0$ to 7.2$)$ & 1 & & 1 & & 1 & \\
\hline Other ethnic group & 6.7 (5.3 to 8.5$)$ & $1.03(0.79$ to 1.33$)$ & 0.846 & 1.07 (0.79 to 1.43$)$ & 0.668 & $1.01(0.75$ to 1.35$)$ & 0.957 \\
\hline \multicolumn{8}{|l|}{ Qualification } \\
\hline Higher degree/first degree/diploma & $5.1(4.2$ to 6.0$)$ & 1 & & 1 & & 1 & \\
\hline A/AS/S levels & $5.5(4.3$ to 7.2$)$ & $1.10(0.80$ to 1.52$)$ & 0.556 & $1.00(0.71$ to 1.4$)$ & 0.998 & 0.97 (0.69 to 1.37$)$ & 0.879 \\
\hline O level/GCSE grades A-C & 6.5 (5.6 to 7.5$)$ & 1.30 (1.05 to 1.62$)$ & 0.017 & $1.06(0.83$ to 1.37$)$ & 0.633 & $1.04(0.81$ to 1.34$)$ & 0.770 \\
\hline GCSE grades D-G & $7.3(5.6$ to 9.5$)$ & $1.48(1.04$ to 2.10$)$ & 0.027 & $1.14(0.78$ to 1.65$)$ & 0.503 & 1.09 (0.75 to 1.58$)$ & 0.660 \\
\hline Other academic qualifications (including overseas) & $5.3(3.1$ to 9.0$)$ & 1.05 (0.59 to 1.89$)$ & 0.865 & $0.98(0.52$ to 1.84$)$ & 0.940 & $0.93(0.49$ to 1.74$)$ & 0.810 \\
\hline None of these qualifications & $9.6(8.1$ to 11.4$)$ & 2.00 (1.55 to 2.59$)$ & $<0.001$ & $1.41(1.02$ to 1.96$)$ & 0.038 & $1.30(0.94$ to 1.81$)$ & 0.114 \\
\hline \multicolumn{8}{|l|}{ Socioeconomic class } \\
\hline Managerial/professional occupation & $5.3(4.5$ to 6.3$)$ & 1 & & 1 & & 1 & \\
\hline Intermediate occupation & 6.7 (5.5 to 8.2$)$ & $1.27(0.97$ to 1.67$)$ & 0.086 & $1.09(0.81$ to 1.47$)$ & 0.562 & $1.06(0.79$ to 1.44$)$ & 0.681 \\
\hline Routine/manual occupation & $7.2(6.3$ to 8.1$)$ & 1.37 (1.11 to 1.69$)$ & 0.004 & $0.88(0.67$ to 1.15$)$ & 0.354 & 0.83 (0.63 to 1.09$)$ & 0.174 \\
\hline Never worked/long-term unemployed & $8.0(6.3$ to 10.2$)$ & $1.54(1.13$ to 2.11$)$ & 0.007 & $0.86(0.57$ to 1.3$)$ & 0.475 & $0.79(0.52$ to 1.2$)$ & 0.267 \\
\hline \multicolumn{8}{|l|}{ Pregnancy characteristics } \\
\hline \multicolumn{8}{|l|}{ Whether this was the first baby } \\
\hline No & $6.8(6.1$ to 7.6$)$ & 1 & & 1 & & 1 & \\
\hline Yes & 6.3 (5.5 to 7.2$)$ & $0.93(0.78$ to 1.09$)$ & 0.361 & $0.94(0.77$ to 1.14$)$ & 0.513 & $0.97(0.79$ to 1.18$)$ & 0.73 \\
\hline \multicolumn{8}{|l|}{ Planning pregnancy } \\
\hline Pregnancy was a surprise & 7.7 (6.8 to 8.7$)$ & $1.38(1.15$ to 1.65$)$ & $<0.001$ & 0.89 (0.72 to 1.09$)$ & 0.259 & $0.93(0.75$ to 1.16$)$ & 0.536 \\
\hline Planned to get pregnant & 5.7 (5.0 to 6.5$)$ & 1 & & 1 & & 1 & \\
\hline \multicolumn{8}{|l|}{ Mother's smoking status during pregnancy } \\
\hline None/gave up & 5.5 (4.9 to 6.1$)$ & 1 & & 1 & & 1 & \\
\hline Kept smoking & $10.4(9.1$ to 11.9$)$ & 2.01 (1.67 to 2.41$)$ & $<0.001$ & 1.59 (1.28 to 1.98$)$ & $<0.001$ & $1.51(1.21$ to 1.89$)$ & $<0.001$ \\
\hline \multicolumn{8}{|l|}{ Child characteristics } \\
\hline \multicolumn{8}{|l|}{ Gender } \\
\hline Boy & $7.8(7.0$ to 8.6$)$ & $1.48(1.23$ to 1.76$)$ & $<0.001$ & $1.51(1.27$ to 1.81$)$ & $<0.001$ & $1.52(1.27$ to 1.81$)$ & $<0.001$ \\
\hline Girl & $5.4(4.7$ to 6.2$)$ & 1 & & 1 & & 1 & \\
\hline
\end{tabular}


Table 2 Continued

\section{Prevalence of child}

\section{limiting}

longstanding

illness in per cent

\section{Characteristics} (95\% Cl)

Gestational age

Very preterm $<32$ weeks

Preterm 32-36 weeks

37-42 weeks

Birth weight in $\mathrm{kg}$

Duration of breast feeding

Never breast fed

$<1$ week

1 week-3 months

$>3$ months

Poverty

Income Poverty

Family income above $60 \%$ of the national median

Family income below $60 \%$ of the national median

Subjective poverty

Subjectively not poor

Subjectively poor

*Adjusted for maternal, pregnancy and child characteristics.

†Adjusted for maternal, pregnancy, child characteristics and poverty.

GCSE, General Certificate of Secondary Education.
20.4 (12.9 to 30.8$)$

10.0 (7.7 to 12.7$)$

$-$

$7.7(6.7$ to 8.9$)$

$5.6(4.3$ to 7.1$)$

$7.7(6.6$ to 8.9$)$

4.9 (4.1 to 5.8$)$
$5.4(4.8$ to 6.0$)$
$6.3(5.7$ to 6.9$)$

\section{Unadjusted} OR $(95 \% \mathrm{Cl})$

Partially adjusted
$\mathrm{OR}^{\star}(95 \% \mathrm{Cl})$

p
Value

Adjusted ORt $(95 \% \mathrm{Cl})$

3.85 (2.20 to 6.73$)<0.001 \quad 0.66(0.34$ to 1.32$)$

1.66 (1.23 to 2.23$)<0.001 \quad 0.57(0.27$ to 1.21$)$

0.2420 .65 (0.33 to 1.29$)$

0.215

$\begin{array}{lll}1 & 1\end{array}$

$0.64(0.55$ to 0.75$)<0.001 \quad 0.76(0.63$ to 0.91$)$

$56(0.27$ to 1.18$)$

0.126

1

1

$0.70(0.52$ to 0.96$) \quad 0.025 \quad 0.77(0.56$ to 1.06$)$

$0.99(0.79$ to 1.24$) \quad 0.928 \quad 1.12(0.89$ to 1.42$)$

0.928
$<0.001 \quad 0.83(0.66$ to 1.05$)$

$\begin{array}{lcc} & 1 & \\ 0.104 & 0.78(0.57 \text { to } 1.07) & 0.119 \\ 0.321 & 1.13(0.90 \text { to } 1.44) & 0.294 \\ 0.113 & 0.84(0.66 \text { to } 1.06) & 0.134\end{array}$

$0.62(0.49$ to 0.77$)$

0.1130 .84 (0.66 to 1.06$)$

.134

5.6 (5.0 to 6.3$)$

$8.8(7.7$ to 10.1$) \quad 1.62(1.35$ to 1.94$)<0.001$

1

$1.18(0.93$ to 1.50$) \quad 0.168$

1

$8.5(7.5$ to 9.6$) \quad 1.62(1.37$ to 1.92$)<0.001 \quad 1.32(1.09$ to 1.58$)$

$1.32(1.09$ to 1.58$) \quad 0.004$ 
As far as we are aware, this is the first nationally representative prospective study examining the association between maternal and child LLI independently of a wide range of different other maternal and child characteristics, and socioeconomic disadvantage. The overall LLI prevalence of $7 \%$ in the children reported here is higher than the prevalence in the 2001 Population Census for England (5\% in 5-year-olds to 7 -year-olds), ${ }^{1}$ but is in line with the LLI prevalence reported in the General Household Survey in 2000-2002 of 4\% in 0-year-olds to 4-year-olds and $8 \%$ in 5-year-olds to 15 -year-olds. ${ }^{18} \mathrm{~A}$ prevalence of $8 \%$ in 5-year-olds to 11-year-olds was also reported in the Family Resources Survey in 2004-2005 which used the Disability Discrimination Act criteria to define the disability in children. ${ }^{19}$

Prenatal and postnatal support for families has been evidenced as important in reducing the odds of poor pregnancy and child-related outcomes. ${ }^{3}$ Public bodies are obliged to promote equality of opportunity for people with disabilities. This includes addressing the barriers and tackling the inequalities in health due to disadvantage and discrimination ${ }^{20}$ including poverty as maternal LLI itself is strongly socially patterned. For families where the parent is disabled, an additional support from health and social services may be required depending on the type and the degree of disability, contextual factors and circumstances of the particular family.

The relative contribution of various factors, such as parental health behaviours, genetic and environmental factors for different childhood LLIs would differ depending on the specific health condition. More research is needed to identify and address the exact mechanisms particularly focusing on modifiable exposures.

\section{CONCLUSIONS}

Although most of the children whose mothers were disabled did not have a limiting longstanding health condition aged 7 years, nevertheless, there was a strong positive association between maternal and child LLI. Healthcare providers, including general practitioners, midwives, obstetricians, paediatricians and health visitors need to be aware of the individual needs of disabled parents during pregnancy and after the child is born. In order to reduce the inequalities experienced by these families, working together with social care services and signposting to other relevant service providers are also required. Further research is needed to clarify the exact nature of the associations for different types of maternal and child disability. This will enable a better understanding about which modifications in the healthcare of pregnant-disabled women could improve their experiences and pregnancy and child health outcomes.

Acknowledgements The authors are grateful to the MCS study team at the Institute of Education and the UK Data Archive and Economic and Social Data Service for making the MCS data available. They would also like to thank Claire Carson and Gry Poulsen at the National Perinatal Epidemiology Unit for some of the derived variables and advice on analysing the MCS dataset, and Tom Shakespeare for helpful comments on an earlier draft.

Contributors DS, JJK, MER and RG contributed to the design, analysis and drafting of the paper and have approved the final version.

Funding This article reports on an independent study which was funded by the Policy Research Programme in the Department of Health (grant number 108/0001). This article reports on an independent study, which was funded by the Policy Research Programme in the Department of Health. The views expressed are not necessarily those of the Department of Health.

Competing interests None.

Ethics approval Ethics approval for the MCS was granted from the Multi-Centre Research Ethics Committee. The work reported here involved secondary analysis of the anonymous MCS data and therefore specific ethics approval was not required.

Provenance and peer review Not commissioned; externally peer reviewed.

Data sharing statement The MCS data are available at http://www.esds.ac.uk/ findingData/mcs.asp.

Open Access This is an Open Access article distributed in accordance with the Creative Commons Attribution Non Commercial (CC BY-NC 3.0) license, which permits others to distribute, remix, adapt, build upon this work noncommercially, and license their derivative works on different terms, provided the original work is properly cited and the use is non-commercial. See: http:// creativecommons.org/licenses/by-nc/3.0/

\section{REFERENCES}

1. 2001 Census-standard tables: Office for National Statistics.

2. Kelly Y, Bartley M. Parental and child health. In: Hansen K, Joshi H, Dex S, eds. Children of the 21st century: the first five years. Bristol: The Policy Press, 2010:249-64.

3. Fair society, healthy lives. Strategic Review of Health inequalities in England post-2010: The Marmot review, 2010.

4. Case A, Fertig A, Paxson C. The lasting impact of childhood health and circumstance. J Health Econ 2005;24:365-89.

5. Department of Education. Supporting families in the foundation years. Department of Health, 2011.

6. Dex S, Joshi H. Children of the 21st century: from birth to nine months. Bristol: The Policy Press, 2005.

7. Hansen K. Millennium Cohort Study first, second, third and fourth surveys: a guide to the datasets. 4th edn. London: Centre for Longitudinal Studies. Institute of Education, University of London, 2010.

8. Plewis I. The Millennium Cohort Study: technical report on sampling 4th edn. London: Centre for Longitudinal Studies, Bedford Group for Lifecourse and Statistical Studies, Institute of Education, University of London, 2007.

9. Agarwal N. Infant and perinatal mortality in England and Wales by social and biological factors, 2009. Statistical Bulletin. Newport: Office for National Statistics, 2010:12.

10. Ketende SC, Joshi $\mathrm{H}$. Income and poverty. In: Hansen K, Joshi $\mathrm{H}$ eds. Millennium Cohort Study Third Survey: a user's guide to initial findings. London: Centre for Longitudinal Studies, Institute of Education, University of London, 2008:234-58.

11. Bradshaw J, Holmes J. Child poverty in the first five years of life. In: Hansen K, Joshi H, Dex S, eds. Children of the 21st century: the first five years. Bristol: The Policy Press, 2010:13-32.

12. Šumilo D, Kurinczuk JJ, Redshaw ME, et al. Prevalence and impact of disability in women who had recently given birth in the UK. BMC Pregnancy Childbirth 2012;12:31.

13. Plewis I. Non-response in a birth cohort study: the case of the Millennium Cohort Study. Int J Soc Res Methodol 2007;10:325-34.

14. Hawkes D, Plewis I. Missing income data in the Millennium Cohort Study: evidence from the first two sweeps. London: Centre for Longitudinal Studies, Institute of Education, University of London, 2008.

15. Sturgis $\mathrm{P}$, Thomas $\mathrm{R}, \mathrm{Purdon} \mathrm{S}$, et al. Comparative review and assessment of key health state measures of the general population. London: Department of Health, 2001.

16. Manor O, Matthews S, Power C. Self-rated health and limiting longstanding illness: inter-relationships with morbidity in early adulthood. Int J Epidemiol 2001;30:600-7. 
17. Read J. Can we count them? Disabled children and their households: Full Research Report. ESRC End of Award Report. Swindon, 2007.

18. Office for National Statistics. General health and use of health services. Living in Britain: Results from the 2002 General Household Survey, 2004.
19. Blackburn CM, Spencer NJ, Read JM. Prevalence of childhood disability and the characteristics and circumstances of disabled children in the UK: secondary analysis of the Family Resources Survey. BMC Pediatr 2010;10:21.

20. Secretary of State for Health report on Disability Equality: Department of Health, 2008. 